\title{
Private Enterprise: The Country Diary of an Edwardian Lady and Female Fan Communities
}

\author{
By Edwards, Sarah
}

EDITH HOLDEN (1871-1920) IS BEST KNOWN TODAY AS THE ARTIST AND naturalist celebrated for her bestselling Country Diary of an Edwardian Lady (written 1906, published posthumously 1977). This book of natural observations, paintings, and poetry remained at the top of the British Sunday Times bestseller list for a recordbreaking sixty-three weeks and sold prolifically throughout the United States, Europe, and the Far East.

In the subsequent decade, public demand for information about the little-known author led to a biography and television drama, while the diary itself inspired an international tourist and merchandising industry which encompassed (to name only a few examples) books of gardening, cookery, crafts, household furnishings, and food.

Some critics were disparaging about the diary's literary and artistic pretensions, claiming it was "not a great literary or historical discovery," and was only written by an "overall unremarkable woman" (Brace, Engen). According to other commentators, the diary represented an idealized or "authentic" past. It was "an exquisite journal of English country life" (Brook). This pleasure was nevertheless a nostalgic pleasure: it portrayed "a life that has gone-and can never return" (Mabey). Holden, in the late twentieth century and beyond, had become an icon of rural English gentility. Such a mantle is somewhat ironic, as Holden was a professionally trained artist from a radical socialist family in Birmingham.

This article will consider how the iconic Edith Holden has come to function in the lives of her late twentieth century fans in Britain, on an individual and collective level. What is the nature of the "nostalgia" she inspires? What role does she play in the oft- derided Edwardian heritage industry? I will aim to look more specifically at the ingredients of Holden fandom: the ways in which she is consumed, and the range of identifications that are possible, especially for women who constitute the majority of her fans. What do we mean by the term "fan" in this context; and how do they perceive the significance of their fandom for themselves? To what extent does existing work on fans account for the desires and practices of Holden enthusiasts? Does the division of "private" and "public" spheres, which is still implicit in the structure of many women's lives, have any resonance for the types and locations of "Holdenism"?

I will investigate this series of questions by foregrounding the observations, and productions, of these women. Thus, I hope to uncover new and unexpected identifications, interactions, activities; and to problematize the critical assumptions of 
both my own initial questions, and the academic discourses I use to contextualize them.

In the few academic works that discuss Holden, she is generally invoked as a representative symbol of the market obsession with nostalgia for the Edwardian period, an epoch conflated with a version of Englishness regarded as suspiciously redolent of white imperialist ideas of nationhood. For example, Robert Hewison was part of a generation of scholars who saw heritage as simplistic, regressive, dangerously right-wing, nationalistic, and a triumph of Thatcherism. He claims, in a typical dilution of Holden's rural antecedents, that heritage icons such as Holden "manages(s) to roll all the pastoralism, snobbery, and retromania of nostalgia into one ball" (Hewison 30). A "taken-for-grantedness" of Holden's popularity recurs in scholarly writing without any reflection on why she is a site of such over-determined meanings.

However, the phenomenon of "fandom" has been extensively researched by feminist critics in recent years (as has audience reception of popular texts more generally). They have provided seminal analyses of other "non-feminist" fan cultures (e.g., Constance Penley has studied Star Trek fan communities who produce their own literature that actively engages in alternative scenarios). However, there is no work on the Holden industry. Yet, as I will demonstrate, the many-faceted Holden merchandise project invites further speculation concerning women's relationship with capitalism and enterprise industry, and thus should hold great appeal for feminist academics. An analysis of the hugely successful dramatization provides further insights into the modes of viewing traditionally devalued "feminine" genres, following on from the work of critics such as Ien Ang on soap opera and Janice Radway on romance. Such theorists have asked by what mechanisms "politically incorrect" forms arouse pleasure, and what are the implications for women's selfimage and political perspective? More generally, these questions are an essential prelude to unpacking the nature of the "pleasures" of nostalgia so unself-consciously noted in writing on Holden's commercial success.

My efforts to understand the specifics of Holden fandom were boosted by an opportunity to participate in a television program which foregrounds one type of fan, the "collector." Collectors' Lot is a daily weekday, half-hour-long, program shown in the United Kingdom. I made an on-screen appeal to anyone who had, or had once had, a collection of Holden material to write to the program to aid me in this research. Each guest appears surrounded by their own paraphernalia, which is intricately arranged and repeatedly surveyed in close-up. The program also emphasizes the centrality of the interest to the person's identity, and the apparent individualism (or, occasionally, exclusive coupledom) of their hobby. For the purposes of the episode, I was encouraged to produce my own narrative of engagement. The fan labels I produced were those of the "childhood fan turned researcher." The interviews are always one on one, and the accompanying relatives or friends who help to arrange their possessions are rarely mentioned. Nevertheless, the program does hint at other contexts by placing these vignettes within a range of communal "heritage" or "fan" enthusiasms.

However, couching my appeal around collections may have limited my response. Are there fans who do not buy the merchandise and identify with Holden differently, for 
example only as television viewers? Would they be likely to watch this type of program? What was the likely socioeconomic and gendered profile and age range of the audience? Luckily I had already made contact with other self- identified fans through Web sites, friends and a newspaper advertisement, all of which enabled me to gain a sense of the wider spectrum of Holden fans. I also hoped that respondents might reveal something of their own backgrounds and indicate their own further fan networks.

Another concern was how my fan labeling, my academic and thus middle-class position, my age, gender, references to childhood enthusiasm, my televisual image (surrounded as I was by merchandise and books), would affect their preconceived attitudes, and subsequent responses to me. This would prove more difficult to ascertain due to the lack of any comparative studies and could only be surmised obliquely, by analyzing patterns of engagement: for example, nuances such as "tone of voice," attempts or otherwise to establish relationships of deference or authority, claims of expertise, assumptions of similarities or differences. Nevertheless my correspondents' engagement with me could in itself reveal possible ranges of fan relationships.

Ultimately I had twenty respondents (and twenty-three letters). The dates of their replies ranged from the day of transmission in November 1999 to March 2000. My replies dated from 23 November (four), 24 November (two), 26 November (two), 29 November, 1 December, 3 December, 6 December, 10 December, 13 December (two), 17 December, 21 December, 6 January, 16 January, 7 March, and 20 March, two were undated. In order to preserve anonymity, yet retain a personal touch, I refer to them by the initial of their given name; where one or more share the same initial, I choose the initial of the surname of the respondent whose given name comes later alphabetically. Clearly the sample is too small to be representative, but certain commonalities that did, as I had hoped, recur, suggested they offered some valuable, if partial, insights into the consumption of Holden past and present. The responses were sharply distinguishable according to the letter-writers' stated intentions in replying. They could be broadly divided into: people with several items which they wished to sell (five); two offering presents; avid "collectors" of the merchandise who wished to contact other enthusiasts (five); women who were keen consumers of the biographical and household artefacts and who had a developed emotional engagement with Holden which they wanted to articulate and share (who wrote to me several times-a total of four separate respondents); and local historians who were not always interested in Holden per se, but felt she might have some connection with their own interests, which I might be able to advance (four). All but one of the latter category were male; all of the other respondents were female and in most cases I could ascertain from personal details that they were in middle age or beyond. Some wrote to me emotionally and even intimately, for example about their life histories; and about everydlay domestic details, as I will go on to discuss. Many looked to me for information. I was also offered items, such as diaries, on the assumption that I was a collector too, for example: "I wish her to accept two Edwardian Lady diaries to add to her collection" (Respondent I). The tone was polite, but often with traces of formality or reserve. For example, some respondents addressed me by my first name, and attempted to establish a friendly relationship by asking me about myself directly: "I'd love, Sarah, to hear more about you" (Respondent A). Others, however, were more 
tentative and felt that it was more appropriate to ask the program makers to mediate on their behalf: "I would be very pleased to hear from her" (Respondent M).

The nature of these replies themselves suggested the usefulness of certain methodologies as a starting-point. They obviously included the seminal feminist works I mentioned earlier, but also theories that were less obviously relevant. This was because my responses indicated identities that are not commonly associated with Holden fandom. For example, they confirm Jenson's theory that according to cultural status fans are frequently subdivided (and often subdivide themselves) into many different categories such as household consumers, collectors, or historians. What, however, are the precise intersections between these fan labels? To what extent are these particular identities transformed within Holden fan culture? What languages and discourses are appropriated to allow fans to reconstruct themselves as "collectors," while maintaining an overlap with other identities? A potentially useful framework of explanation was Pierre Bourdieu's model of a "cultural economy," whereby audiences possess financial or aesthetic "cultural capital" of differing degrees of prestige according to education, class, and so on, which determines how they are "labeled" as fans. This theory has been modified by Fiske, and others, by the "adding in" of determinants including gender. This seemed to offer the flexible and nuanced model I needed, due to the seeming variety in class, gender, education, and age of my respondents. The work by critics such as Penley on "active fandom" also seemed promising, given the intense activity of many respondents, in areas as diverse as selling and writing.

This section, then, will consider the relevance of such approaches to a definition and appreciation of Holden "fans." I found them partially useful, but I often had to move beyond them and formulate my own theories to enable me to understand how Holden is used in daily life. As I unravel the fascinating and diverse source material that was so willingly given to me, I will argue that the example of Holden has in itself something new to offer our understanding of how fandom is understood.

The "Consuming" Fan

I have a copy of The Country Diary of an Edwardian Lady by Edith Holden September 1977 issue. I'd appreciate it if you would advise me if you know of anyone who would like to purchase it and at what price. I also have a copy of The Illustrated Lark Rise to Candleford by Flora Thompson 1983 issue. (Respondent B)

"I have two small vases and one handcream dispenser from the 'Country Diary collection' made by Royal Winton. Could you tell me if these are of any value. They are date marked 1977" (Respondent L). These writers' adoption of a mercantile discourse meant that their letters were, strictly speaking, irrelevant and opportunistic replies to my request for information. But I was nevertheless intrigued to discover why even an "academic" appeal about Holden memorabilia should elicit such responses.

Popular accounts of Holden fandom present the phenomenon as easily understandable within conventional models of fan psychology. The industry colludes with the media in crudely construing consumption as the most significant factor. Such attitudes are broadly in line with the dominant theories of cultural consumption proposed by 
Adorno and Horkheimer in the 1940s, which maintained that a mass capitalist "culture industry" such as the Holden enterprise produces standardized products geared to an economy which enslaves passive audiences to the status quo by means of "mass deception." The category of respondents who saw their memorabilia in terms of monetary value foregrounded the implicit theme within Holden culture and related academic writing, that of the much- maligned relationship between women and enterprise.

Throughout the more upmarket press and the industry's own marketing material, there is a traditional location of woman as passive housewife/consumer who buys indiscriminately. As an industry spokesman characteristically opines:

The whole situation has to be romanced a little, to bring a little bit of theatre to the shopper . . . Rich with self-image and the lifestyle they want to project, it's a total image and that's what co-ordination is all about. ... for the customer it's about aspiration to an image, saying to the world "I am this kind of person" . . there's now much more awareness of lifestyle, generated by the Dallas and Dynasty exposure over here.

\section{(Meyrick)}

The Holden fan is surrounded by a set of negative connotations that can be unpacked from this statement alone. The passages evoke a familiar caricature of a passively aspirational and uneducated consumer, manipulated by an industry offering a stereotypically 1980s version of Englishness with a soapy American gloss. Feminist critiques of traditional models of fandom have observed that the fan is often equated with femininity, immaturity, lower class status. For example, Raphael Samuel's work implicitly reproduces this model in his account of Country Dwry-influenced household culture: he claims that "it provided the motifs" for the Edwardian nostalgia craze and "confirmed broderie anglaise as a more or less mandatory decorative frill." His inclusion of words such as "mandatory" re- creates the image of female enslavement to fashion without undermining his left-wing, profeminist credentials (Samuel 66).

The industry's "trans-generic" quality is the basis for the general contempt for Holden merchandise buyers. The marketing and purchasing of everything from watercolors to slippers is a frequent source of bemusement: "Is everything starting to turn into everything else? Art, commerce and fantasy are mixed up. I see a future in which an author will no longer submit a mere manuscript" (Garner). Statements such as these provide some indications of the reviewers' own ideological agendas and fears. Many of the professional journalists who criticize the industry most fervently, such as the one quoted above, are female and seem to feel the need to distance themselves personally from such attributes. Female commentators typically qualify a relatively appreciative or at least astonished account of the Holden merchandising range with the caveat that it is, for example, "too wishy-washy for my taste" (Whitehorn). These "intellectual women" may be right to claim that the Holden enterprise is a configuration of domesticity and enterprise welded together by a "totalising" set of values. But how far does its development within the parameters of the 1980s marketing theory of the "total lifestyle concept" (which is the very essence of the "Holden dream") reinstate, reconfigure, or challenge the model of the "consuming 
female fan?" It is a market/consumer relationship that demands careful reexamination.

\section{Reconfiguring Holden Consumption}

A close analysis of this group of letters reveals more complicated attitudes towards the possessions the writers wish to sell than is at first evident. One respondent vaunts:

I wonder if the lady who had the lovely collection of memorabilia of an Edwardian lady would be interested in a 1979 calendar ... in its original envelope and in perfect condition (complete with its original price on the back!). I would be quite willing to send it to her, if she would like to have a look at it, it's so beautifully illustrated.

(Respondent J)

while another remarks:

I have a vinyl LP (which was a gift to me in the 1980s) which I do not wish to keep anymore. I've only played it once, it's in an excellent condition and I wonder if you or a friend would be interested in buying it from me for 6. (Respondent E)

Here both respondents (even the writer who listened to her LP only once) reveal varying degrees of aesthetic appreciation of the items, despite wanting to sell them. Somewhat paradoxically, they demonstrate a personal involvement with their unused possessions, in their pride in keeping them in pristine condition. In her second letter to me, Respondent $\mathrm{J}$ draws her unwanted calendar into a narrative of family history:

My daughter bought it for me when she was a very young girl. It was never "hung up" but I have threatened many times to cut it up and frame its pictures, but I've resisted the temptation hence its good condition. It's moved house with us several times, it's been offered to grandchildren but nobody wanted it.

In these examples Holden merchandise is part of the respondents' mundane household effects, and because it is simply "part of the furniture" is not cherished but is nevertheless bound up with housewifely pride, personal history, and homely familiarity. Thus, it acquires some limited value for its owner. The simultaneous foregrounding of family relations, the beautification of the home ("I've threatened many times to cut it up and frame the pictures"), and price labels which have themselves become markers of historical value ("complete with its original price on the back!"), indicates an intriguing conflation of monetary, historical, and emotional value which indicates that the act of consumption can be drawn into a highly individual nostalgia. The common meanings attached to both of the terms "consumption" and "nostalgia" are problematized.

However, these women's mental and material involvement with Holden merlchandise does not mean they identify themselves as collectors, or as fans. For example, in her second letter, Respondent $\mathrm{J}$ responded to my question about her own interest in Holden with the following: "I can't say I have any particular interest in Edith Holden and the diary, except that I think it is so beautifully drawn and presented." They were one-off buyers who responded in a moderate degree to the marketing claims regarding the household or decorative uses of the products. However, at a deeper discursive 
level, their subsequent attitude toward, and uses of, the items, indicates they were more influenced by various discourses of collecting, enterprise, and the "total lifestyle concept," than their limited purchases seem to indicate. They responded to Collectors' Lot as opportunists who foregrounded the financially enterprising aspects of collecting fandom. These owners' desire to sell household goods may indicate the economic neediness of many female Holden consumers, and their eager recognition and espousal of the circulation of Holden merchandise in fan networks. Indeed this may be a strong impetus to create such networks. I was clearly "identified" as a likely link.

In a very different configuration of femininity and enterprise, the following respondent's tone starkly combines a history of consumption, the "hard sell," and a narrative of artistic inspiration, production, and pride. As an artist and businesswoman she recognizes the potential of the Holden industry to satisfy both aspects of her identity, and espouses an increasingly "public" version of originally domestic enterprise:

I am a Worcestershire-based sculptor of collector porcelain dolls. Have my own interpretation of a rather grand "Edwardian Lady" in various costume styles. Was inspired by the diary on original publication. You are welcome to view. I will give you exact instructions when you call to make arrangements. (Respondent P)

Thus the letter writers actually demonstrate vastly different configurations of aesthetic appreciation, creativity, and financial flair dependent on their particular life histories and the way Holden has become entangled with them. Even insofar as they identify themselves as buyers, they do it in complicated ways. In these feminized, domesticated versions of enterprise culture, the public and private, and the mercantile and the affectional, are not rigidly divided.

\section{Private Consumption?}

A second group of respondents wrote to offer me Holden items as gifts:

May I have the address of a lady named Sarah Edwards, who appeared on Collectors' Lot on 23rd November, as I wish her to accept two Edwardian Lady diaries to add to her collection. Alternatively, should the stamped parcel be sent to you for redirection? (Respondent I)

"I have a book called 'The Language of Flowers' given to Mother by Father Aug 18th 1913. I would like to know if it is of use to your collection?" (Respondent C). These women are "Holdenists" who wish to communicate with a fellow enthusiast.

However, it is noteworthy that even in their attempts at a personal interaction, they still implicitly employ the mercantile discourse, in their denial of a wish to sell. The first respondent is keen to stress that she has even paid for the postage herself, while the second emphasizes the personal, rather than mercantile, value of her book. This fan identity can be most fruitfully analyzed in the case of a third respondent, who wrote to me on Holden notepaper, a choice that she brought to my attention in both of her letters: "my granddaughter bought me this notepaper for my birthday and Christmas" and again, "my granddaughter bought this writing paper and a photograph album, decorated with the Edwardian Lady flowers and foliage" (Respondent $\mathrm{H}$ ). It is 
noticeable that she chooses to emphasize that the paper was a treasured and aesthetically pleasing present, from a female relative; and in her decision to write on it to me, there was a sense that this merchandise was being offered in the same vein. Later she asked for my help in obtaining a video copy of the television dramatization, and ended her final letter with the sentence: "thanks to you I now can look forward to my family providing me with a copy as a Christmas present." She accepted my information as another present, which in turn facilitated the pleasing anticipation of another gift. The link to Christmas was also made by several correspondents whose replies were delayed until December: several women sent me Christmas cards. The association of Christmas with not only consumerism, but with the affectionate giving and receiving of presents, was an important motivating factor in these women's consumption of the Holden merchandise.

These gestures are a key feature of the pleasures of a brand of Holden fandom, which extends beyond the narrow definition of socially aspiring, materialistic female "gift culture" assumed by critics such as Samuel. Radway claimed that her readers saw romances as a "gift" you give yourself and this provides a starting-point for understanding the pleasure these women experience (Radway 91). Letter writing is a momentous event: apparently an individual act, but one that simultaneously solidifies a fan network. Several women were eager to enter into a correspondence, and thanked me profusely for replying to their letters: "it is lovely news to learn that you share the same interest with somebody else, who is also as enthusiastic as yourself (Respondent $\mathrm{M}$ ); and "thank you so much for answering my letter, it's so good to find someone who is so interested in the Edwardian Lady" (Respondent S).

One can gain pleasure from the act of writing on beautiful Holden notepaper, like Respondent $\mathrm{H}$, which is increased by feeling it will probably be treasured as another "collectable" piece of merchandise. Similarly, Respondent S offered me photographs she had taken herself of the Dartmoor beauty spots that are featured in Holden's diary. So the one-to-one communication affirms these women's sense of self- worth as unique beings who can make a distinctive individual contribution by their own deployment of Holden. The letters provide insights into feminine fan relationships in which a polite gift culture is linked to the essential politeness and privacy of Holden fandom.

Indeed, the concept of domestic privacy is undoubtedly a key modifier in the use of most theoretical models in relation to Holden fandom. Holden fans reconfigure their ascribed role as passive domestic consumers in multiple ways. The complex binary of public and private spheres is, in these turn-of-the-century female groupings, convoluted and paradoxical. Though a television broadcast is "public," the Collectors' Lot event was framed to facilitate private exchange and encouraged the viewers to respond on a "woman to woman" basis. Holden fandom is generally conducted in the home and in small local groups. The letters to me were friendly, enthusiastic, yet deeply reserved: for example, the women protested "I hope you won't be offended" (Respondent S) and "I hope you do not mind my writing," when I had asked them to (Respondent A).

There are no national fan clubs or conventions. Even the few Web sites are not interactive, but enforce passivity as they celebrate their activity as fans. For example, one Texan fan who discusses her garden, only briefly mentions the inspirational effect 
of the diary in its design-"my friend knew instinctively Edith Holden and I would jive!"; and she then provides a picture of both ("Eeyore"). This is a typical pattern: a simple layout paying tribute to the effect of the diary on the writer's life and its tangible results. There are seldom any e-mail or other addresses provided; no chat lines or message boards have been formed. The community is enlarged by cumulative individual contacts rather than by any sense of collectivity, much less collective movement.

Mapping the Imaginary Spaces of Fan Activity

\section{Leisure}

Several familiar fan discourses combine to position Holden within the mental and physical spaces of many women's leisure time. Yet another keyword, in both Holden fan culture and feminist fan literature, is "therapeutic." For example, the writer of the Country Diary knitting book, Annette Mitchell, discusses her reasons for writing the book by narrating the nature of her interest in crafts. She "discovered the therapeutic value of craft at a very young age. I sat on the edge of the road, consoling myself with my knitting" ("Keeping Crafts Alive"). John Fiske (35) suggests that for this type of "mundane" fan, their relative lack of activity keeps them on the "boundary" of common definitions of active, enthused fans. For many Holden fans her image is essential, but in a daily, nonobtrusive way. The time lapse between the broadcast of my television appeal and the date of some responses indicates that many viewers had a desire to reply, but perceived it as nonurgent.

A more concrete, and indeed intriguing, indication of the diary's significance for this group of fans is that the Bible is a minor trope in many accounts of its material function in people's lives. The publishers claim that readers' letters demonstrate that "the diary is becoming a bedside book, kept alongside the Bible and dipped into during moments of reflection" ("Edith's Edwardian diary"). The diary's copyright holder, Rowena Stott, describes fans who implicitly mimic the Bible by keeping the diary laid open at the day's entry (Stott, Interview.) The publisher's quotation aptly summarizes the qualities commonly attributed to the Bible as a social as well as a religious document. Clearly a diary can perform similar functions. At the level of language and discourse the diary is descriptive, and easy to read according to a familiar set of cultural codes. The genre is cyclical, reflective, daily, even mundane; and (in the form of the nature diary) provides minimum disruption to the status quo.

The notion olf "escape" is another recurring trope. The commonly noted, and often shifting and ambivalent, alternative meanings of this term in feminist literature are of leaving behind an unsatisfactory present and/or imagining a Utopian future (Radway; Fiske 113). Yet most "daydreaming" is complex, as those who indulge in it acknowledge that such fantasizing is a self-conscious, playful, and often mentally stimulating game. These are also important components of Holden fandom.

For example, many of the letter-writers wrote to me because they wanted to obtain a video copy of the television dramatization. They eagerly declared that they "would dearly love to see the film again" (Respondent H) and "I went to a video shop in Kingsbridge and they had it so fingers crossed they will get it for me" (Respondent S). All of the women had seen the dramatization before, but laid emphasis on their desire 
for repetitive (or cyclical?) viewing. For example, Respondent F declared "I will enjoy watching my video again and again." Similarly, the normally mild-mannered Respondent H narrates how: "I was careless enough to go over the tape with another program. The period I lost (to my extreme chagrin) was the summer of 1906-June to August. I was very mad with myself." Respondent F enlarged on the pleasures of this repetitive viewing: "I really enjoyed the tape . . . I love the era of Edwardian Lady . . . that era was very relaxed, no rush, tearing around, people had time to stop and look at nature."

Both women evoke the familiar Edwardian rural idyll of endless summer and a slower pace of life. However, they simultaneously acknowledge the subjective, momentary, and nonpolitical nature of this pleasure. They desire an instant and vividly satisfying sense of escape from a mundane (rather than horrific) world to a sensually exciting one. These understated sentences mark the high point in letters that otherwise discuss a daily round of housework and caring for elderly relatives. There is little sense of the industry evoking any kind of obviously feminist dissatisfaction, or desire for political change.

Critics who have studied the characteristics of devalued cultural forms including melodrama and soap opera offer useful insights into the pleasures these women experience. They uncover the mechanisms that arouse pleasure in spite of the often conservative view of sex roles propagated by these genres (Ang ch. 1,2). The Holden dramatization shares some characteristics with such texts. Like soap opera, it elevates ordinary life and family rituals. Its structure around the seasons of the year provides comforting stability and repetition, which may also explain the women's desire for repetitive viewing. It offers the pleasure of the "aimless glance" of visual stylization, whereby the natural surroundings are sumptuously photographed and offered up to the viewer's gaze. The characters, including Holden herself, are largely archetypal, as is the case in melodrama (The Country Diary of an Edwardian Lady). For many women, then, the series represents only beauty, relaxation, and a release from everyday pressures. But the word "only" undervalues the importance of this pleasure. The series is another gift. But because television viewing does not require expensive ongoing purchases, as does the Holden "total lifestyle concept," it is one that they feel entitled to give themselves.

\section{Education}

However, the serial's "empiricist realist" element-the nature documentary strand of this "drama-documentary"-is also welcomed for its bland, apparently nonpolitical educative basis. Respondent F declared: "I really enjoyed the tape, as I belong to a natural history club, I found it very educating." This emphasis on the educative benefits of the Holden industry is implicit elsewhere: "Olton Heritage gives a very interesting and telling description of the environs and people who lived there during the Edwardian period. I found it to be quite fascinating" (Respondent H). Another respondent opines:

I had no idea her family had published girls' fiction and essays. I just adore the old form of essays and when I get the chance at old book sales try to pick up any I can find. I love writing, art and history. (Respondent A) 
However, the industry is primarily associated with the discourses surrounding the "private sphere" of leisure and amateurism. These discourses act as a source of constant tension in debates about "worth" between fans, the industry, and critics. Radway has suggested that these concepts are in competition with the more culturally prestigious discourses of work and professionalism (Radway 105). Indeed, this industry often appears to resent its status as popular culture, and thus adopts verbal and nonverbal strategies of disguise. The industry's suggestion that you can buy back the past is covered with edifying talk of Englishness. The following is from a 1987 catalogue:

Country Diary has beauty, innocence and charm which hark back to simple values of years ago. It provides a window on a forgotten world, satisfying a yearning for unspoilt countryside, an unhurried lifestyle and an appreciation of country pursuits. It also encapsulates a kind of Englishness which is appreciated all over the world. I think it embodies the essence of English country life. These days, when life is so hectic, everyone wants to get back to that lost country way of life, even, and perhaps especially, if they live in town!

\section{(The Country Diary Collection)}

Here, what Ang (ch. 3) has called the "populist" discourse, which maintains, in opposition to the "ideology of mass culture," that everyone has a right to enjoy whatever pleases them regardless of aesthetic status, is inflected with the apparently overarching Holden values of artistry and worthy middle-class English morality.

This discourse is an important dimension of the ways in which fans interpret their own consumption of the Holden material. Many critics, such as John Fiske (36), have noted that some members of fan cultures may use higher cultural aesthetic standards to assess popular cultural forms, especially if they themselves are from more dominant social groups. Many Holden fans identify with middle-class values that then determine their chosen fan identity. For example, Carol Andrews, who co-authored Olton Heritage, lives in the house where Holden wrote the diary. She has re-created it as an Edwardian home, but is keen to emphasize that she regards her work as an act of public service: "it is very special to the local community. We are preserving it for future generations" (Walker). She thus chooses to see herself not as a particularly conspicuous consumer of domestic merchandise, but as a community facilitator.

\section{Collecting}

I classified many of the letter writers as "collectors" because they identified themselves as such. For example, Respondent $\mathrm{S}$ initially established her identification with me on these terms: "I am also a collector." Respondent L similarly declared that "I am also a great admirer of Edith Holden's Country Diary book . . I collect china . . . and anything else to do with the diary such as prints, books, bedlinen and curtains." They lay emphasis on the quality and visual beauty of the merchandise: that, for example, "they are really beautiful plates" (Respondent $S$ ). Their letters are also characterized by detailed lists of items, and by narratives that demonstrate their resourceful, methodical, "professional" approach. They recount with pride how they found items in sales, indicating how they have succeeded in spite of their often 
precarious economic situation: "I have recently acquired from an antiques fair, a set of twelve plates. I am very pleased to have found them." She later expands:

I have the curtains and bedlinen and the border round the walls . . a also a 1990 calendar plate which I bought at a sale and a book called the country diary companion. I saw it in a second-hand shop in Poole, Dorset. (Respondent S)

Once again, I was identified as a likely link in another fan network. Respondent B asked me to respond to her list by providing a list of my own items, explaining that "it is nice to know what is/ was available to seek." However, although the collecting element of Holden fandom overlaps with the mercantile discourse, it thus taps into a more serious, methodical vein and thus constitutes yet another alternative fan discourse. Jenson (19 - 20) notes that "collecting" is often seen as a more prestigious form of fan activity. One might also suggest, however, that these activities have been made more visible and respectable through the less intellectually prestigious medium of enterprise culture. Hence all of these groups of fans belong to different "interpretative communities" and have acquired a more prestigious type of "cultural capital" (Fiske 36). They locate the diary and its associated products within the realms of history, education, religion, and the studied collection of beautiful objects.

\section{Liberated Women}

The most ardent female fans combine together several fan identities. The secluded, upwardly mobile and educative characteristics of Holden fandom all appear to contribute to its actively enabling, as well as its escapist side, for them. Thus the "welding together" of multiple discourses results in one of the most complex images in Holden fan culture: the "liberated" woman. One of my most voluble and emotionally engaged respondents was eager to stress the importance and relevance of this identity: "people like Edith were lucky to indulge their art considering the misery of most of society. They seem a great deal more liberated than later women also" (Respondent A).

Pippa Guard, the televisual Edith Holden, employed similar discourses of identification, aspiration, and liberation in a magazine interview. She claimed Holden was "the sort of woman most of us could identify with and not a lady in that sense at all." The article works to dispel the negative clonnotations of ladyhood by outlining Guard's own behavior. There are admiring accounts of Guard's plucky efforts at Edith's own favorite activities of hill- climbing and cycling when she filmed the dramatization (signaling physical sturdiness); but also her refusal to wear corsets because she believes an "intellectual, artistic woman like Edith" would have refused to do so (signaling freedom of physical and intellectual expression). The final reason for this refusal (and a section header) was because Guard had a twenty-four inch waist anyway when she was in "good shape" (now apparently bowing to physical stereotypes of femininity). Once again, a range of feminine identities seem somewhat crudely "added on" to each other. Any identifiable degree of self-consciousness about this process might suggest a postmodern effort to choose from a range of available identities. But instead, as the "cover lady" of Family Circle (a significant revision of the more familiar term) Guard is presented as a suitably "updated" role model for women, underlined by the accompanying statement: "Pippa Guard: Return of the Edwardian Lady" (Churchill). 
"Liberation," then, is explicitly identified with the Edwardian middle-class woman. However, this range of femininities does allow fans to reconfigure themselves as entrepreneurial producers but within the private domestic sphere. The industry advocates the revival of various traditional feminine activities. The spin-off books based on the diary illustrations promoted relearning Edwardian crafts, cookery, knitting, gardening, and a range of other home- based activities. Many have quite polemical introductions: for example, "Edwardian cooks, like their predecessors, took pride and pleasure in their work. It is now more fashionable to take short cuts. We are part of a tradition which remains both lively and productive." But the authors take account of modernity and feminism. They place considerable emphasis on the hard work and skill involved in these tasks. The introduction to the Holden cookery book reads: "such collections indicate a conscientious preoccupation with detail and a practical concern with their subject" (Harding, Introduction).

Such remarks deny that traditionally feminine qualities signal weakness or passivity. These qualities are unfavorably projected onto Victorian women. Pippa Guard claims that "women were emerging from the Victorian yoke and becoming educated and liberated. They could make their own decisions as to what liberation meant, though. There were no television and newspapers telling them how a liberated woman should behave" (McCormack). Holden the (re-constructed) Edwardian lady comes to represent a type of ideal middle ground between Victorian passivity and the disturbing modern identities that Guard obliquely refers to. But how empowering is this image of the modern, liberated woman? How do the female fans attempt to live out this ideal?

\section{Inspiration}

The letter writers with the strongest emotional engagements provide some limited indications. They acknowledge Holden as a role- model and aspire to imitate her values and achievements in a contemporary context. Thus, they both strongly identify with, and idealize, Holden. They openly claim that she is "inspirational": yet another keyword. For example, Holden has inspired fans to produce their own diaries and the same respondent told me with evident pride: "I keep Edith's books in my bedroom always to help me with my painting" (Respondent A). Female fans are then inspired by each other's achievements, as was evident in some of the responses to me: "you've inspired me to collect a bit more to do with Edith" (Respondent A) and "I was so excited to learn of your interest in this wonderful subject and I wonder if you can help me" (Respondent S). Fan relationships are clearly important in legitimating their desires and productions.

One writer in particular attempted to establish a fan identification with me by laying claim to a common feminine identity, exemplified by Holden: "I feel very much that Edith is a kindred spirit-do you?" (Respondent A). It was notable however, that in the narratives of emotional engagements with Holden, to be found in Web sites, letters and newspaper reports, there is a strong link to invalidism and disappointment. Respondent A gave me an intimate description of her battle with ME and agoraphobia. Another fan relates how her mother developed glaucoma but still perseveres with her Country Diary-inRuenced needlework designs (Kellogg). For these women Holden culture has provided examples of creatively satisfying activity which can be undertaken by a secluded individual and provide a moderate, rather than intimidating, degree of intellectual challenge. Is Holden's supposed mediocrity 
empowering? Does being a Holden fan dilute, or compensate for, societal inequalities?

\section{Private/Public Enterprise?}

Most of the Holden authors begin writing out of their fan enthusiasm. Ina Taylor, the biographer, is positioned as a fan in publicity material: she "has always enjoyed writing as a hobby," but due to this amateur background "admits too to being a little nervous of all the radio, television and press interviews" (Jones). Many writers on female fandom have claimed that fans are actively engaged and write their own texts; but in this case many of the key writers and actors locate themselves as fans, are constituted as fans by the industry and press, and themselves influence more traditionally located fans.

One of the most curious features of this "private" activity, then, is that it ultimately finds its way into the "public" sphere. It is increasingly obvious that one of the unique features of the Holden industry is a blurring between production and consumption at the mass-market level. Even inside their books production and consumption are blurred. They are all "do-it-yourself (DIY)- oriented" and encourage the reader to be proactive within the text. The layout of such volumes affords plenty of space to make one's own observations alongside the writer's instructions, giving the impression of a genuinely interactive reading experience. The reader is addressed incessantly as a serious student who may ultimately reach the writer's level of expertise: "they have to write most of the book themselves." Indeed as many of the writers were fans and amateurs this is a likely goal. These concepts in themselves undermine notions of the passive consumer and incorporate the domestic into the public sphere (Gorer, "Introduction").

\section{Conclusions}

There is no sense among Holden fans that they are settling for the mediocre:

Went walking round the Devon lanes this morning with my springer Gem and saw the dog mercury in flower and lots of lesser celandines and primroses on the banks. I would like to think that Edith was walking with us.

She later says: "that would make my dream come true (to obtain the television series) ... I wonder what happened to all her paintings and books, it would be lovely to own one" (Respondent S), while another writer declares: "I would dearly love to see it (the television series) again before I go to some other place" (Respondent H). As these extracts suggest, there is seldom any tone of irony among Holden fans: either of the type identified by Ang, whose sample accepted the "ideology of mass culture," enjoyed laughing at the text and attempted to "dominate" it; or of a more sophisticated type who admit to enjoying such popular cultural forms, making their own meanings and thus, in a reversal, making it seem "cool," even subversive, to like such material. (Examples of this type of ironic fandom might include tribute bands such as the Abba show with the playful name, Bjorn Again.) This apparent absence of irony indicates limited self-consciousness among Holden enthusiasts. They to some extent conform to stereotypes of women's emotional natures, and their uncritical consumption of capitalist produce. 
For the characteristic middle-aged or elderly Holden fan who responded to me, any doubts may be denied out of a wish to embrace a seductive and oft-trumped ideal of Englishness that, in its rhetoric, seamlessly glosses over inequities of gender, class, or race. It is likely that the Holden industry actively deters potential fan communities who are more politically self-conscious. Its identification with white middle-class Englishness may alienate the very groups likely to produce ironic readings: one cannot, for instance, imagine a gay Holden following. The industry's anomalous position between official and mass culture may also be a factor. The attempts at higher cultural status immediately deflate any tongue- in-cheek approach. Its entirely asexual, even anodyne, projection of daily life produces an effect of rather bemusing innocence in a postmodern age. The sumptuousness of the products-the rich colors, lavish photography-may hint at a sensually erotic coloration. But this cannot be fully appreciated by those who do not consume the Holden productions.

Furthermore, when many of the most ardent fans are using the diary and merchandise on a daily basis and, more rarely, using their own spin-off productions to make money, the industry is too contemporary to satirize. The Holden industry constantly re- negotiates current debates around Englishness, femininity, and enterprise culture in ways that complicate, rather than demolish, popular stereotypes of Holden fans. It provides models of womanhood that celebrate ordinary domestic skills while encouraging their money-making potential in the public sphere. It refuses to be labeled "bad mass culture" by insisting on its moralistic function. This capitalist industry allows, even encourages, considerable space for inventiveness by its customers, who frequently become producers in the spirit of Holden's own triumphant success. They apparently want wholeness, simplicity, and ordinariness as an escape from an ironic, cynical, rellativist, postmodern age. It is my belief that Holden as icon is created out of a series of paradoxes. But I also believe that Holden fans generally would feel that such a thesis is irrelevant to their fan identity and sensibility. And thus they throw down their own challenge to current cultural theory, which locates the validity, and dignity of fan cultures in their subtlety and multiplicity. The mass of Holden fans long for, and cheerfully embrace, a simple and stereotypical model of adoring fandom.

\section{Works Cited}

Adorno, Theodor, and Max Horkheimer. "The Culture Industry: Enlightenment as Mass Deception." The Cultural Studies Reader. Ed. Simon During. London: Routledge, 1993: 31-41.

Ang, Ien. Watching Dallas: Soap Opera and the Melodramatic Imagination. London: Methuen, 1985.

Brace, Keith. "Fragrance from the Fields of Edwardian Olton." Birmingham Post 18 June 1977: 2.

Brook, Danae. "A Country Romance Blossoms Again After Seventy Lost Years." Daily Express 1 July 1977: N. pag.

Churchill, Jill. "Pippa Guard: Return of the Edwardian Lady." Family Circle 18 April 1984: 49-52. 
The Country Diary Collection. Tenth Anniversary Promotion Package. Richard Webb Ltd., 1987.

The Country Diary of An Edwardian Lady. Central Television. 22 Feb.-16 May 1984.

"Edith's Edwardian diary becomes a world classic." Sunday Independent 12 Nov. 1978: N. pag.

"Eeyore" (1999). "The Neglectful Gardener." 2 Dec. 1999 (http:// www.htcomp.net/weis/gardenneglect.html).

Engen, Rodney. "Some Diaries of Victorians and Edwardians." Book World Advertiser May 1982: 6-7.

Fiske, John. "The Cultural Economy of Fandom." The Adoring Audience: Fan Culture and Popular Media. Ed. Lisa A. Lewis. London: Routledge, 1992: 30-49.

Garner, Lesley. "Good Books." Good Housekeeping Dec. 1980: 189.

Gorer, Richard. The Country Diary Garden Notes. Exeter: Webb and Bower, 1984.

Harding, Alison. The Country Diary Book of Cookery Notes. Exeter: Webb and Bower, 1984.

Hewison, Robert. The Heritage Industry: Britain in a Climate of Decline. London: Methuen, 1987.

Holden, Edith. The Country Diary of an Edwardian Lady. Exeter: Webb and Bower, 1982.

Jenson, Joli. "Fandom as Pathology: The Consequences of Characterisation." The Adoring Audience: Fan Culture and Popular Media. Ed. Lisa A. Lewis. London: Routledge, 1992: 9-29.

Jones, Mandy. "Ina brings secret author to life." The Journal 12 Sept. 1980: N. pag.

"Keeping crafts alive." Pins n. d.: 29

Kellogg, Pamela. "The Stitcher-Cross Stitching." 3 July 1999

(http://www.crossstitch.about.com).

Mabey, Richard. "A Fastidious Pen." The Times 16 June 1977: 14.

McCormack, Mary. "The Country Diary of an Edwardian Lady." Annabel March 1984: 12-13.

Meyrick, Penny. "Fashioned Images." Cabinet Maker and Retail furnisher 11 Oct. 1985: 24-25. 
Penley, Constance A. "Feminism, Psychoanalysis and the Study of Popular Culture." Cultural Studies. Eds. Lawrence Grossberg, Gary Nelson, and Paula Treichler. New York: Routledge, 1992: 479-500.

Radway, Janice A. Reading the Romance: Women, Patriarchy and Popular Literature. London: Verso, 1984.

Samuel, Raphael. Theatres of Memory: Past and Present in Contemporary Culture. Vol. 1. London: Verso, 1994.

Stott, Rowena. Interview with Sarah Edwards. November 1999.

Walker, Hannah. "Edwardian style for this lady!" Solihull News 15 Oct. 1989: 21.

Whitehorn, Katharine. "The Tea-Cosy of the Book." The Observer 1983: N. pag.

Dr Sarah Edwards is Lecturer in English Studies at the University of Strathclyde, Glasgow, UK. She has published articles and chapters on women's diaries and popular culture, and is writing her first book on nostalgia and Edwardian culture in the later twentieth century. 